\title{
Specificity of radioluminescence of polycrystalline and composite scintillators based on organic single crystals granules
}

\author{
T.E.Gorbacheva
}

\author{
Institute for Scintillation Materials, STC "Institute for Single Crystals", \\ National Academy of Sciences of Ukraine, \\ 60 Lenin Ave., 61001 Kharkiv, Ukraine
}

Received 25 December, 2013

The luminescence and scintillation characteristics of polycrystalline and composite materials based on stilbene, anthracene and the $p$-terphenyl doped with 1,4-diphenyl-1,3butadiene are studied. A comparative analysis of the influence of deep traps on the radioluminescence spectral composition and yield is performed. Quenching of radioluminescence is caused by the presence of deep traps, which leads to a shortening of the radioluminescence pulse decay time and to decrease of the light output. The revealed regularities under radiative excitation are compared with similar results obtained under excitation by photons of light in the visible region.

Исследованы люминесцентные и сцинтилляционные характеристики поликристаллических и композиционных материалов на основе стильбена, антрацена и $n$-терфенила, активированного 1,4-дифенил-1,3-бутадиеном. Проведен сравнительный анализ влияния глубоких ловушек на спектральный состав и выход радиолюминесценции. Тушение радиолюминесценции обусловлено наличием глубоких ловушек, что приводит к сокращению фронта затухания импульса радиолюминесценции и падению величины светового выхода. Выявленные закономерности при радиационном возбуждении сравниваются с аналогичными результатами, полученными при возбуждении фотонами света в видимой области.

Специфіка радіолюмінесценції полікристалічних і композиційних матеріалів на основі гранул органічних монокристалів. Т.Є.Горбачова.

Досліджено люмінесцентні та сцинтиляційні характеристики полікристалічних i композиційних матеріалів на основі стильбену, антрацену і $n$-терфенілу, активованого 1,4-дифеніл-1,3-бутадієном. Проведено порівняльний аналіз впливу глибоких ловушок на спектральний склад і вихід радіолюмінесценції. Гасіння радіолюмінесценції обумовлено наявністю глибоких ловушок, що призводить до скорочення фронту спаду імпульсу радіолюмінесценції і падінню величини світлового виходу. Виявлені закономірності при радіаційному збудженні порівнюються з аналогічними результатами, отриманими при збудженні фотонами світла у видимій області.

\section{Introduction}

Organic fluorescent materials having low effective atomic number, have an advantage over inorganic systems at registration of short-range particles ( $\alpha$ - and $\beta$-radiation). One of the ways to improve the detection efficiency of short radiation is to increase the area of the sensing element of the recording setup. However, the most effective 
organic scintillators - organic single crystals, cannot be obtained in large diameter while maintaining high scintillation characteristics [1]. Detectors with large areas can be made on the base of composite materials [2], and by sintering (cold and hot pressing) [3]. In each of named types of organic scintillators shallow, medium depth and deep traps may occur [4, 5]. Traps are most often centers of structural origin. If we consider the structural traps, shallow and medium depth traps are usually defined by imperfection of molecular packing in the grains and deep traps occurring at grain boundaries can be interpreted as accumulation of dislocations. They typically occur at the boundaries of the unit structures of the single crystal. Dynamic traps when the charge carrier is localized at some of the molecules are also possible. Charge carrier creates polarization environment and self-trapes in this molecule. Dynamic traps are the most shallow traps for charge carriers. In consequences to polarization interactions trap depth for charge carrier increases on the order of $0.1 \mathrm{eV}$. Dynamic traps do not occur under optical excitation [4]. The presence of deep traps should lead to suppression of radio luminescence, which leads to shortening of decay front and to decrease of scintillation signal intensity.

This work is devoted to a comparative study of the influence of deep traps on the spectral composition and radioluminescence yield of polycrystalline and composite organic scintillators $[1,3]$.

\section{Preparation of polycrystalline and composite scintillators}

For this study polycrystalline (PC) and composite samples (CS) based on stilbene, $p$-terphenyl doped with 1,4-diphenyl-1,3-butadiene (TF), and anthracene were manufactured. Granules with a grain size of $2.2-$ $2.5 \mathrm{~mm}$ were used to produce the samples [6]. TF and stilbene granules were made by crushing the corresponding single crystal ingot under the layer of liquid nitrogen. Anthracene granules were made from purified by zone melting primary anthracene ingot [7].

Prepared stilbene, activated $\mathrm{TF}$ and anthracene samples had diameter of $30 \mathrm{~mm}$ and thickness of $5.0 \mathrm{~mm}$. Samples were pressed under a pressure of uniaxial compression of $30 \mathrm{MPa}$ and temperature of $120^{\circ} \mathrm{C}$ for stilbene, $165^{\circ} \mathrm{C}$ for $\mathrm{TF}$ sample and $140^{\circ} \mathrm{C}$ for anthracene. Exposure time at this

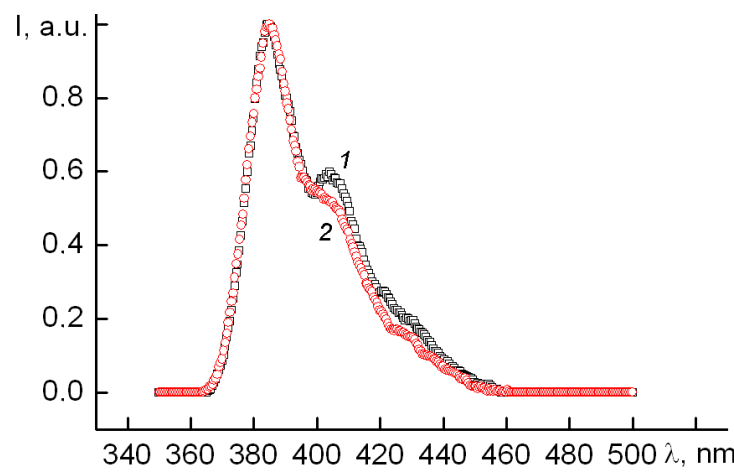

Fig. 1. Radioluminescence (1) and photoluminescence (2) spectra based on stilbene.

pressure and temperature was 60 minutes. After this time, the pressure was reduced to atmospheric in 10 minutes and temperature was lowered to RT in 120 minutes. In addition, single- and multilayer composite scintillators were prepared. Composite scintillators were prepared by introducing scintillation granules into dielectric gel. Dielectric gel composition Silgard 527 was used as a basis $[2,6]$. The containers were made of plexiglass. The inner diameter of the container was $30 \mathrm{~mm}$ and the thickness of base was $2 \mathrm{~mm}$. The thickness of multilayer scintillator was $5.0 \mathrm{~mm}$ and of single-layer scintillators about $1.5-2.0 \mathrm{~mm}$.

Radioluminescence spectra of scintillators were recorded using KSVU 23 spectrometer. Luminescence was excited by X-ray generator REYSI operated at voltage of $40 \mathrm{kV}$ and current of $30 \mathrm{~mA}$ [8].

Relative light yield of samples was calculated by comparing the amplitude spectra with the standard. Spectra were recorded using the following sources: ${ }^{137} \mathrm{Cs}$ (conversion electrons of $0.624 \mathrm{MeV}$ energy) and ${ }^{239} \mathrm{Pu}(\alpha-$ particles of $5.15 \mathrm{MeV}$ energy). As a photo receiver we used photomultiplier Hamamatsu R-1307, as a reference scintillator - a single crystal of anthracene $\varnothing 30 \times 5 \mathrm{~mm}^{2}$ and the single crystal of $p$-terphenyl doped with 1,4-diphenyl-1,3-butadiene $\varnothing 30 \times 5 \mathrm{~mm}^{2}$.

Optical transmittance of samples was measured by a spectrophotometer "Hitachi$330 "$ with an integrating sphere [9].

\section{Results and discussion}

Fig. 1 shows radioluminescence (curve 1) and photoluminescence (curve 2) spectra of scintillators based on stilbene. 


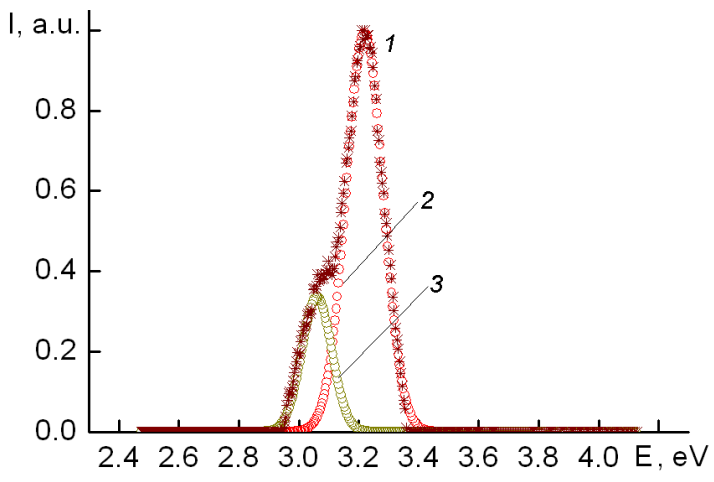

a)

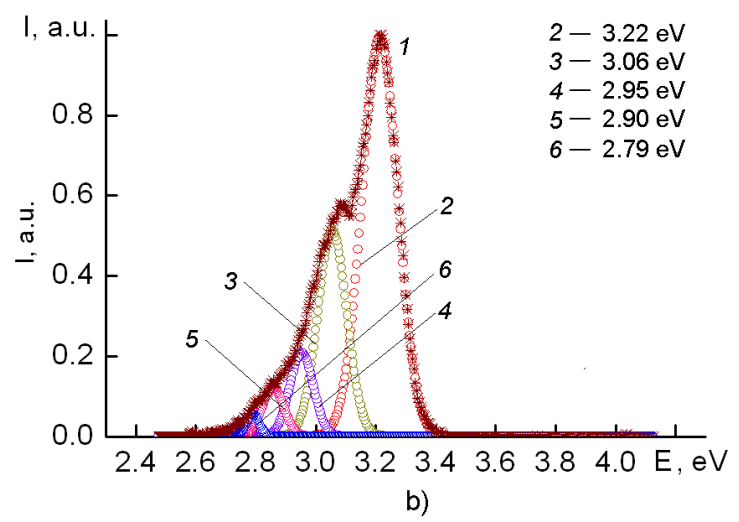

b)

Fig. 2. a) Radioluminescence spectra of single crystal scintillator based on stilbene in the energy scale and the results of approximation by sum of Gaussian curves; b) Radioluminescence spectra in the energy scale (1) and the result of their approximation by sum of Gaussian curves (2-6) of the polycrystalline sample based on stilbene with grain size of $2.2-2.5 \mathrm{~mm}$.

Table 1. Energy levels of trap centers in monocrystalline, polycrystalline and composite scintillators based on stilbene

\begin{tabular}{|c|c|c|c|c|c|}
\hline Sample & $E_{0}, \mathrm{eV}$ & $E_{1}, \mathrm{eV}$ & $E_{2}, \mathrm{eV}$ & $E_{3}, \mathrm{eV}$ & $E_{4}, \mathrm{eV}$ \\
\hline Single crystal & 3.2 & $\begin{array}{l}3.05 \\
(0.4)^{*}\end{array}$ & & & \\
\hline Polycrystalline detector & 3.2 & $\begin{array}{l}3.06 \\
(0.6)\end{array}$ & $\begin{array}{c}2.96 \\
(0.22)\end{array}$ & $\begin{array}{c}2.88 \\
(0.18)\end{array}$ & $\begin{array}{l}2.81 \\
(0.1)\end{array}$ \\
\hline Single-layer composite detector & 3.2 & $\begin{array}{l}3.05 \\
(0.3)\end{array}$ & $\begin{array}{c}2.96 \\
(0.16)\end{array}$ & & \\
\hline Multi-layer composite detector & 3.2 & $\begin{array}{l}3.07 \\
(0.6)\end{array}$ & $\begin{array}{c}2.97 \\
(0.21)\end{array}$ & $\begin{array}{c}2.81 \\
(0.17)\end{array}$ & $\begin{array}{l}2.65 \\
(0.09)\end{array}$ \\
\hline
\end{tabular}

* In Table 1 for given energy levels in the samples the relative intensity of the peaks $\left(I_{I}\right)$ is shown in parenthesis. Intensity of the peak at energy $E_{0}$ is taken as unity.

Dynamic traps do not appear under optical excitation, as there is no polarization in the absence of uncompensated charge carrier. Therefore, their influence can be seen only on radioluminescence spectrum.

Figure 2 shows radioluminescence spectra of single crystal (Fig. 2a) and polycrystalline (Fig. 2b) stilbene scintillators. Analysis of radioluminescence spectra of single-crystal (SC), polycrystalline (PC), single-layer (SCD) and multi-layer (MCD) composite scintillators showed the presence of characteristic bands with maxima at $\lambda_{0}=385 \mathrm{~nm}$, as well as additional peaks at $\lambda_{1}=405, \lambda_{2}=415$, $\lambda_{3}=425$, which corresponds to energies $E_{0}=3.2, E_{1}=3.06, E_{2}=2.95, E_{3}=2.89$, $E_{4}=2.79$ (Table 1). The difference between energies $E_{0}$ and $E_{1}, E_{0}$ and $E_{2}, E_{0}$ and $E_{3}$, $E_{0}$ and $E_{4}$ is equal to $E_{10}=0.13, E_{20}=0.18$,
$E_{30}=0.28 \mathrm{eV}, E_{40}=0.42 \mathrm{eV}$, respectively. For anthracene: $\lambda_{0}=446 \mathrm{~nm}$, as well as additional peaks at $\lambda_{1}=473, \lambda_{2}=498, \lambda_{3}=533$, $\lambda_{4}=575 \mathrm{~nm}$ which corresponds to the energies $E_{0}=2.77, E_{1}=2.62, E_{2}=2.49, E_{3}=2.32$, $E_{4}=2.15 \mathrm{eV}$. The difference between energies $E_{0}$ and $E_{1}, E_{0}$ and $E_{2}, E_{0}$ and $E_{3}, E_{0}$ and $E_{4}$ is equal to $E_{10}=0.15, E_{20}=0.28$, $E_{30}=0.45, \quad E_{40}=0.62 \mathrm{eV}$, respectively. For TF $\lambda_{0}=380$ (low intensity), $\lambda_{1}=395$ and $\lambda_{2}=420 \mathrm{~nm}$, as well as additional peaks at $\lambda_{3}=440, \lambda_{4}=470, \lambda_{5}=505 \mathrm{~nm}$. In the energy scale we get $E_{0}=3.23 \mathrm{eV}, E_{1}=3.12 \mathrm{eV}$, $E_{2}=2.97 \mathrm{eV}, E_{3}=2.79 \mathrm{eV}, E_{4}=2.64 \mathrm{eV}$, $E_{5}=2.47 \mathrm{eV}$. The difference between $E_{0}$ and $E_{1}, E_{0}$ and $E_{2}, E_{0}$ and $E_{3}, E_{0}$ and $E_{4}$, $E_{0}$ and $E_{5}$ is equal to $E_{10}=0.15, E_{20}=$ $0.29, \quad E_{30}=0.44, \quad E_{40}=0.59, \quad E_{50}=$ $0.82 \mathrm{eV}$, respectively. $E_{2}$ corresponds to the 
Table 2. Energy levels of trap centers in monocrystalline, polycrystalline and composite scintillators based on anthracene

\begin{tabular}{|c|c|c|c|c|c|}
\hline Sample & $E_{0}, \mathrm{eV}$ & $E_{1}, \mathrm{eV}$ & $E_{2}, \mathrm{eV}$ & $E_{3}, \mathrm{eV}$ & $E_{4}, \mathrm{eV}$ \\
\hline Single crystal & 2.77 & $\begin{array}{l}2.62 \\
(0.25)^{*}\end{array}$ & & & \\
\hline Polycrystalline scintillator & 2.77 & $\begin{array}{c}2.62 \\
(0.38)\end{array}$ & $\begin{array}{l}2.49 \\
(0.2)\end{array}$ & $\begin{array}{l}2.32 \\
(0.1)\end{array}$ & $\begin{array}{c}2.15 \\
(0.05) \\
\end{array}$ \\
\hline Single-layer composite scintillator & & $\begin{array}{c}2.63 \\
(0.24) \\
\end{array}$ & $\begin{array}{r}2.48 \\
(0.06) \\
\end{array}$ & & \\
\hline Multilayer composite scintillator & 2.77 & $\begin{array}{c}2.62 \\
(0.36)\end{array}$ & $\begin{array}{c}2.49 \\
(0.05)\end{array}$ & & \\
\hline
\end{tabular}

* In Table 2 for given energy levels in the samples the relative intensity of the peaks $\left(I_{I}\right)$ is shown in parenthesis. Intensity of the peak at energy $E_{0}$ is taken as unity.

Table 3. Energy levels of trap centers in monocrystalline, polycrystalline, and composite scintillators based on $p$-terphenyl doped with 1.4-diphenyl-1,3-butadiene

\begin{tabular}{|c|c|c|c|c|c|c||}
\hline Sample & $E_{0}, \mathrm{eV}$ & $E_{1}, \mathrm{eV}$ & $E_{2}, \mathrm{eV}$ & $E_{3}, \mathrm{eV}$ & $E_{4}, \mathrm{eV}$ & $E_{5}, \mathrm{eV}$ \\
\hline Single crystal & 3.23 & 3.12 & 2.97 & 2.79 & 2.64 & 2.47 \\
& & $(33)^{*}$ & $(29)$ & $(12.7)$ & $(4.7)$ & $(1.3)$ \\
\hline Polycrystalline detector & 3.26 & 3.11 & 2.97 & 2.82 & 2.67 & 2.44 \\
& & $(16.7)$ & $(24.2)$ & $(9.7)$ & $(4.8)$ & $(1.16)$ \\
\hline Single-layer composite detector & 3.25 & 3.12 & 2.96 & 2.8 & 2.64 & 2.44 \\
& & $(50)$ & $\mathbf{( 3 6 . 5 )}$ & $\mathbf{( 1 7 . 5 )}$ & $\mathbf{( 6 . 5 )}$ & $(2)$ \\
\hline Multilayer composite scintillator & 3.2 & 3.12 & 2.97 & 2.81 & 2.65 & 2.44 \\
& & $(20)$ & $(18.2)$ & $\mathbf{( 9 . 6 )}$ & $\mathbf{( 5 . 4 )}$ & $(1)$ \\
\hline
\end{tabular}

* In Table 3 for given energy levels in the samples the relative intensity of the peaks $\left(I_{I}\right)$ is shown in parenthesis. Intensity of the peak at energy $E_{0}$ is taken as unity.

maximum of 1,4-diphenyl-1,3-butadiene emission. The luminescence of $p$-terphenyl in doped TF crystal is quenched by transfer to 1,4-diphenyl-1,3-butadiene. The concentration of 1,4-diphenyl-1,3-butadiene in the crystal is $10^{-2} \%$ [10]. Therefore, as the main peak, we took $E_{0}$.

Tables 1,2 and 3 shows respectively the energy levels of trap centers of monocrystalline, polycrystalline, and composite scintillators based on stilbene, TF, anthracene giving in brackets the relative intensity of the corresponding peak. The intensity of the peak at energy $E_{0}$ was taken as unity. Therefore, intensity of the other peaks of stilbene and anthracene were less than unity, and of single crystal doped TF greater than unity. All samples have the trap centers with close energies associated with grain boundaries $\left(\Delta E_{10}\right)$. Values of these trap centers contributions indicates that the traps with the same depths, that occur in the SC, PC, CD, have different contributions, i.e. the probability of their occurrence is different. $\Delta E_{30}, \Delta E_{40}, \Delta E_{50}$ can be attributed as deep traps. In HPD and MCD relative contribution of deep traps is more than in single crystals. This is because the introduced granules are oriented randomly. Combination of granules with slight offset of their borders will be more likely than in the case of grown SC.

Let us assume that the peaks that make the asymmetry in the low-energy part of the spectrum (Fig. 2) are due to the presence of traps of structural origin. In this case, the direct excitation of the respective fluorescent centers should also lead to luminescence. To test this assumption, the excitation spectra for samples based on stilbene, $\mathrm{TF}$ and anthracene were recorded. Under irradiation with wavelengths 385,405 and $425 \mathrm{~nm}$ of the samples based on stilbene luminescence maxima were at $\lambda_{1}=390 \mathrm{~nm}$, $\lambda_{2}=410 \mathrm{~nm}, \lambda_{3}=430 \mathrm{~nm}$. Under irradiation with wavelengths $445,470,495,530$ 
Table 4. Decay time of monocrystalline, polycrystalline, single- and multi-layer composite scintillators based on stilbene obtained by excitation with light of following wavelengths: $\lambda_{1}=385 \mathrm{~nm}$ (I), $\lambda_{2}=401 \mathrm{~nm}$ (II), $\lambda_{3}=425 \mathrm{~nm}$ (III), $\lambda_{4}=445 \mathrm{~nm}$ (IV)

\begin{tabular}{|c|c|c|c|c||}
\hline \multirow{2}{*}{ Sample on the base of stilbene } & \multicolumn{4}{|c||}{ Decay time, ns } \\
\cline { 2 - 5 } & I & II & III & IV \\
\hline Single crystal & 3.44 & 3.73 & 0.26 & 4.81 \\
Polycrystalline scintillator & 3.04 & 3.21 & 4.47 & - \\
Single-layer composite scintillator & 3.42 & 3.63 & 0.94 & 4.73 \\
Multilayer composite scintillator & 3.03 & 3.24 & 4.6 & - \\
\hline
\end{tabular}

Table 5. Decay time of monocrystalline, polycrystalline, single- and multi-layer composite scintillators based on $p$-terphenyl doped with 1.4-diphenyl-1.3-butadiene recorded under excitation at the following wavelengths: $\lambda_{1}=380 \mathrm{~nm}$ (I), $\lambda_{2}=395 \mathrm{~nm}$ (II), $\lambda_{3}=420 \mathrm{~nm}$ (III), $\lambda_{4}=440 \mathrm{~nm}$ (IV), $\lambda_{5}=470 \mathrm{~nm}(\mathrm{~V}), \lambda_{6}=505 \mathrm{~nm}(\mathrm{VI})$

\begin{tabular}{|c|c|c|c|c|c||}
\hline \multirow{2}{*}{ Sample on the base of TF } & \multicolumn{5}{|c||}{ Decay time, ns } \\
\cline { 2 - 7 } & I & II & III & IV & 4.88 \\
\hline Single crystal & 3.53 & 3.84 & 4.2 & 4.63 & 5.6 \\
\hline Polycrystalline scintillator & 3.53 & 3.65 & 4.2 & 4.81 & 5.01 \\
\hline Single-layer composite scintillator & 3.42 & 3.63 & 3.94 & 4.42 & 5.01 \\
\hline Multilayer composite scintillator & 3.3 & 3.44 & 3.7 & 4.23 & V \\
\hline
\end{tabular}

Table 6. Decay time of monocrystalline, polycrystalline, single- and multi-layer composite detectors based on anthracene recorded under excitation at the following wavelengths: $\lambda_{1}=445 \mathrm{~nm}$ (I), $\lambda_{2}=470 \mathrm{~nm}(\mathrm{II}), \lambda_{3}=495 \mathrm{~nm}$ (III), $\lambda_{4}=530 \mathrm{~nm}(\mathrm{IV}), \lambda_{5}=575 \mathrm{~nm}(\mathrm{~V})$

\begin{tabular}{|c|c|c|c|c|c||}
\hline \multirow{2}{*}{ Sample on the base of anthracene } & \multicolumn{5}{|c||}{ Decay time, ns } \\
\cline { 2 - 6 } & I & II & III & IV & V \\
\hline Single crystal & 29.97 & 28.5 & 27.76 & 27.94 & 27.94 \\
Polycrystalline scintillator & 25.78 & 25.3 & 27.05 & 36.34 & 36.34 \\
Single-layer composite scintillator & 27.89 & 27.6 & 28.84 & 22.5 & 22.5 \\
Multilayer composite scintillator & 23.45 & 21.98 & 23.68 & 32.65 & 32.65 \\
\hline \hline
\end{tabular}

and $575 \mathrm{~nm}$ of the samples based on anthracene luminescence maxima were at $\lambda_{1}=$ $450 \mathrm{~nm}, \lambda_{2}=475 \mathrm{~nm}, \lambda_{3}=500 \mathrm{~nm}, \lambda_{4}=$ $535 \mathrm{~nm}, \lambda_{5}=580 \mathrm{~nm}$, respectively. Under irradiation with wavelengths of 380 , 395, $420,440,470,505 \mathrm{~nm}$ of the samples based on the TF luminescence maxima were at $\lambda_{0}=385 \mathrm{~nm}, \lambda_{1}=400 \mathrm{~nm}, \lambda_{2}=425 \mathrm{~nm}$, $\lambda_{3}=445 \mathrm{~nm} ; \lambda_{4}=475 \mathrm{~nm}, \lambda_{5}=510 \mathrm{~nm}$. With the same excitation wavelengths, decay kinetics was recorded for monocrystalline, polycrystalline, single-layer and multi-layer scintillators. The results are shown in Table 4, 5, 6 .

Figure 3 shows the results of a study of the scintillation characteristics of scintillators based on stilbene, TF and anthracene obtained by irradiation with $\alpha$-particles (Fig. 3a) and $\beta$-particles (Fig. 3b). Axis of ordinates shows the relative light output and on the abscissa numbers $1,2,3,4$ - respectively denote the results obtained for SC, SCD, MKD scintillators and PC. This arrangement was chosen because the contribution of deep traps (see Table 1, 2, 3) increases when moving $\mathrm{SC} \rightarrow \mathrm{SCD} \rightarrow \mathrm{MCD} \rightarrow \mathrm{PC}$. Thus, the scintillation output of samples decreases with increasing contribution of trap centers $I_{i}$ (Tables 1 , 2,3 ), i.e. with an increase in probability of occurrence of deep structural traps. These data are also consistent with the hypothesis that the increase in the number of deep traps is accompanied by an increase in the probability of outflow on them of charged states with subsequent localization for long time. Indeed, the time of localization $\tau_{t}$ on the 

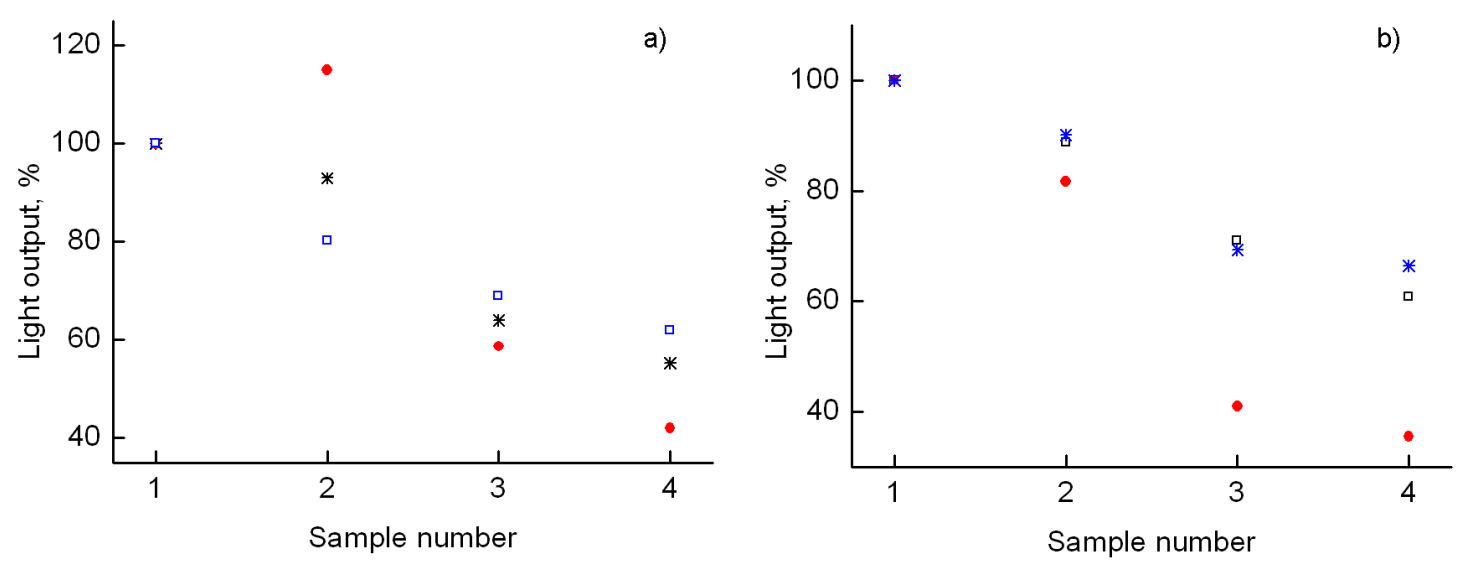

Fig. 3. Results of the study of the scintillation properties of scintillators based on stilbene (asterisk), TF (squares) and anthracene (circles), obtained by irradiation with $\alpha$-particles (a) and $\beta$-particles (b)

trap with depth $E_{t}$ can be estimated as [4]:

$$
\tau_{t}=\frac{1}{v}\left[\frac{E_{t}}{k T}\right],
$$

where $v$ is frequency factor. For the systems with temperatures above the Debye temperature $\left(T_{D} \sim 140 \mathrm{~K}\right)$ it is equal to $v=2.9 \cdot 10^{12} \mathrm{~s}^{-1}$ [4]. For anthracene we get $\tau_{t 3}=1.1 \cdot 10^{-5} \mathrm{~s}$ and $\tau_{t 4}=0.7 \cdot 10^{-2} \mathrm{~s}$, and for $\mathrm{TF} \quad \tau_{t 3}=7.7 \cdot 10^{-6} \mathrm{~s}, \tau_{t 4}=2.5 \cdot 10^{-3} \mathrm{~s}$ and $\tau_{t 5}=17.16 \mathrm{~s}$, for stilbene $\tau_{t 4}=3.58 \cdot 10^{-6} \mathrm{~s}$. Outflow of charged states to the deep traps reduces the number of excited molecules formed by recombination of the charge states for a time comparable with the duration of the formation of the fast component of the scintillation pulse. Such a loss in the number of formed excited molecules should lead to a reduction in light output, which is confirmed experimentally (Fig. 3).

It is informative to compare the kinetics of radioluminescence of monocrystalline, polycrystalline and composite scintillators. A typical example of this dependency is shown in Fig. 4: rise time of the polycrystalline sample is longer relatively to one of a single-crystal sample, and the decay time of scintillation pulse of polycrystalline sample is shorter than the one of the single crystal. A similar situation has been analyzed in details in [3]. As shown in this work the increase in rise time may occur due to the localization of charge carriers on small traps if the duration of such localization is shorter than the scintillation flash. Therefore, this effect is mainly observed in the localization of charge carriers on dynamic traps. Decreasing in the fall time may occur due to the outflow of carriers to deep traps of structural origin. If

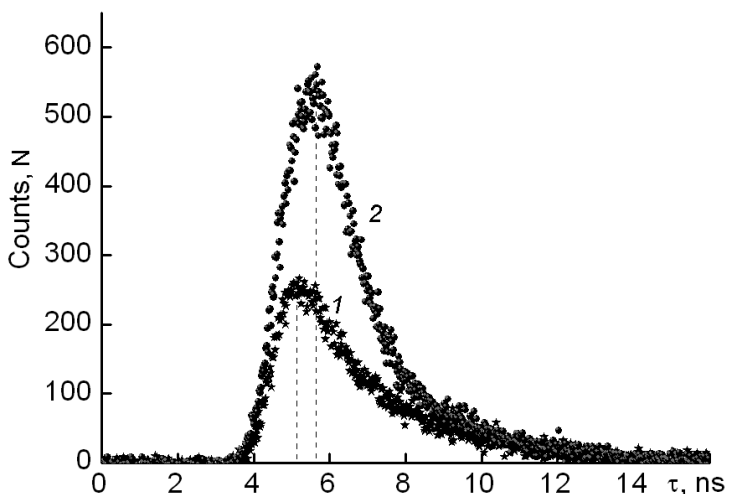

Fig. 4. Radioluminescence decay curves obtained by irradiating with $\beta$-particles from radionuclide source ${ }^{90} \mathrm{Y}+{ }^{90} \mathrm{Sr}$ of single crystal (1) and polycrystalline (2) scintillators based on doped $p$-terphenyl; $N$-number of pulses.

localization time of charge carrier on the trap is longer than decay time of the fast component of the scintillation flash, the effect of the outflow of charge carriers will reduce the number of recombination during the formation of the fast component of the scintillation pulse. This in turn will cause a decrease in the number of excited molecules and, consequently, the number of scintillation photons that contribute to the scintillation pulse. Comparison of luminescence decay times for samples based on stilbene, anthracene and TF are shown in Table 4, 5, 6. For stilbene, anthracene and TF time values $\tau_{3}, \tau_{4}, \tau_{5}$ are higher than the corresponding value of the decay time constant.

Terms of light passage through the scintillator can be characterized by the value of its transmission [9]. The averaged transmission was obtained by averaging optical transmittance measured at five different 


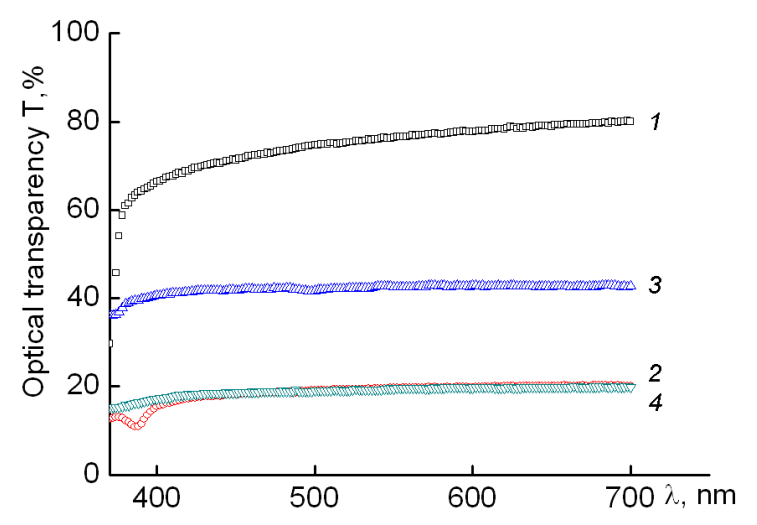

Fig. 5. Transmission values of samples based on anthracene: 1 - single-crystal, 2 - polycrystalline, 3 - single-layer and $4-$ multilayer composite scintillators.

points of the sample surface. Transmittance is given in percentage relatively to the air.

Average values of the optical transmission of samples based on anthracene are shown in Fig. 5. Considered dependences indicate that transparency decreases in the following order $\mathrm{SC} \rightarrow \mathrm{SCD} \rightarrow \mathrm{MCD} \rightarrow \mathrm{PC}$. All graphs shows a decrease of anthracene transparency in the anthracene absorption band. Such dependences is observed in stilbene and TF with the only difference that in TF transparency decrease in the absorption band of $\mathrm{TF}$ and 1,4diphenyl-1,3-butadiene. Results of investigation of optical transmittance (Fig. 5) indicates that the optical transmission increases with decrease in the number of scattering boundaries. These data correlate with the given above measurements of the light output of samples ( $5 \mathrm{~mm}$ thick) obtained by irradiation with short-range particles (Fig. 3).

In particular, this result points to the effect of the optical transmission in the visible region of the spectrum on the light output of samples excited by short-range radiation. Thus, light scattering additionally contributes to the decrease in the intensity of radioluminescence of composite and polycrystalline samples. For polycrystalline and SCD influence of transparency on the value of the scintillation flash is more significant under the excitation with $\alpha$-particles than when excited by $\beta$-particles. This is because the range of $\alpha$-particles is less than $30 \mu \mathrm{m}$ while one of conversion electrons is $2 \mathrm{~mm}$.

\section{Conclusions}

Completed study show that the presence of imperfections in the structure of scintil- lators leads to the following features of the formation of scintillation signal: charge carrier traps both small and deep reveal themselves under ionizing excitation and increase in their number leads to a decrease in the light output. Under optical excitation dynamic traps are not appear as there is no polarization in the absence of uncompensated charge carrier. Short-term localization of charge carriers on the dynamic traps leads to increase in the rise time of scintillation pulse.Outflow of carriers to deep traps leads to quenching effect of radio luminescence if the capture of charge carriers in these traps significantly higher than the decay time of the scintillation pulse. In this case, the quenching of the radioluminescence, expressed in shortening of decay time of the flash and in decrease in the intensity of the scintillation signal takes place. Light scattering additionally contributes to the decrease in the intensity of radioluminescence of composite and polycrystalline samples.

The author wish to acknowledge Dr. N.Z. Galunov for the leadership through the execution of this work. The author also wish to thank N.L.Karavaeva for preparation of composite samples, I.V. Lazarev for preparation of polycrystalline samples, V.A. Litichevskiy for radioluminescence measurements, O.G. Viagin for measurements of photoluminescence and decay time and V.D. Panikarskaya for optical transmittance measurements.

\section{References}

1. S.V.Budakovsky, N.Z.Galunov, N.L.Karavaeva et al., IEEE Trans. Nucl. Sci., 54, 2734 (2007).

2. N.Z.Galunov, B.V.Grinyov, N.L.Karavaeva et al., IEEE Trans. Nucl. Sci., 56, 904 (2009).

3. N.Z.Galunov, J.H.Baker, S.V.Budakovsky et al., J. Luminescence, 102-103, 464 (2003).

4. E.A.Silinsh, V.Capek, Organic Molecular Crystals, Amer. Inst. of Physics, New York (1994).

5. T.E.Gorbacheva, N.Z.Galunov, I.V.Lazarev et al., J. Appl. Spectrosc., 81, 164 (2014).

6. N.L.Karavaeva, O.A.Tarasenko, N.Z.Galunov, Pat. 37010 Ukraine.

7. N.Z.Galunov, I.V.Lazarev, A.D.Samohin, Author's Certificate No. a201312050 Ukraine.

8. V.A.Litichevskyi, A.D.Opolonin, S.N.Galkin et al., Instrum. Exper. Techn., 56, 436 (2013).

9. T.E.Gorbacheva, N.Z.Galunov, V.D.Panikarskaya, I.V.Lazarev, Functional Materials, 18, 335 (2011).

10. S.V.Budakovsky, N.Z.Galunov, I.V.Lazarev et al., Functional Materials, 18, 466 (2011). 